\title{
O microempreendorismo em questão: elementos para um modelo alternativo
}

\author{
Luiz Inácio Gaiger * \\ Andressa da Silva Correa **
}

\section{Resumo}

Este artigo objetiva contrastar o modelo convencional de fomento ao empreendedorismo de pequeno porte, centrado no desenvolvimento de competências individuais, com os aportes propiciados pela reflexão em torno das experiências de empreendedorismo associativo, hoje em evidência no campo da Economia Solidária. Sumariam-se no texto os principais pontos de destaque resultantes da análise crítica do empreendedorismo de pequeno porte desenvolvido sob os auspícios do SEBRAE - Serviço Brasileiro de Apoio às Micro e Pequenas Empresas, predominante como referência conceitual e como prática no Brasil. Aborda-se a seguir a visão de empreendedorismo estribada em estudos sobre empreendimentos nos quais os elementos relacionais e de cooperação cumprem funções relevantes, explicitamente. Tais elementos conduzem a um modelo alternativo, distinto dos padrões convencionais quanto à compreensão e ao atendimento das necessidades das organizações de economia popular, sejam negócios de cunho individual ou familiar, sejam empreendimentos coletivos, como grupos de produção informais, associações e pequenas cooperativas.

Palavras-chave: microempreendedorismo, economia popular, informalidade, Economia Solidária, associativismo.

* Professor Titular da Universidade do Vale do Rio dos Sinos (Unisinos - São Leopoldo, RS), coordena a Cátedra da UNESCO Trabalho e Sociedade Solidária e a Rede de Investigadores Latino-americanos de Sociologia Social e Solidária. Diretor da Sociedade Brasileira de Sociologia. Endereço eletrônico: gaiger@unisinos.br.

*** Mestranda em Sociologia na Universidade Federal do Rio Grande do Sul. Membro do Grupo de Pesquisa em Economia Solidária, no qual foi bolsista de Iniciação Científica. Endereço eletrônico: andressa_teatro@yahoo.com.br. 


\title{
Introdução
}

\begin{abstract}
A s considerações apresentadas neste artigo traduzem alguns Ados resultados do projeto de pesquisa Microempreendedorismo e Associativismo em Países de Desenvolvimento Periférico, desenvolvido em parceria entre o Programa de Pós-Graduação em Ciências Sociais da Universidade do Vale do Rio dos Sinos (Unisinos, São Leopoldo/RS), o Centro de Estudos Sociais (CES, Coimbra) e o Cruzeiro do Sul - Instituto de Investigação para o Desenvolvimento José Negrão (ICS, Maputo). O objeto focalizado pela pesquisa diz respeito ao empreendedorismo praticado por trabalhadores associados em pequena escala, formalmente ou tacitamente, no tocante às peculiaridades das organizações econômicas correspondentes e ao modo como a associação e a cooperação modelam e potencializam a gestão empreendedora. ${ }^{1}$
\end{abstract}

As peculiaridades nacionais e os respectivos estados de conhecimento sobre o tema conduziram as pesquisas empíricas a assumirem focos ligeiramente diferentes em cada país. Em Portugal, a questão principal relacionou-se a práticas e dispositivos de cooperação latentes nas micro e pequenas empresas e nos pequenos negócios informais, buscando-se discernir os caminhos que tais elementos propiciam em direção a arranjos formalmente associativos. Em Moçambique, buscou-se de identificar condutas empreendedoras latentes ou explícitas no interior das organizações econômicas familiares e comunitárias, nas quais predominariam relações de comensalidade (RAZETO, 1990), distintas das relações de cooperação, mas igualmente orientadas por princípios de reciprocidade.

No Brasil, a análise esteve centrada em dois âmbitos distintos. De um lado, o empreendedorismo de pequeno porte existente em empresas individuais quanto ao regime jurídico e de gestão. Sua principal expressão empírica, do ponto de vista das práticas, é a micro e pequena empresa; do ponto de vista da concepção e da ação promocional, o "modelo SEBRAE". De outro lado, o empreendedorismo de pequena escala desenvolvido em organizações

1 Projeto financiado pelo CNPq, por intermédio do Programa de Cooperação em Matéria de Ciências Sociais para a Comunidade de Países de Língua Portuguesa - CPLP. 
econômicas coletivas quanto à propriedade e à gestão. Nesse caso, a delimitação empírica recaiu sobre os empreendimentos registrados pelo primeiro Mapeamento Nacional da Economia Solidária, compreendendo grupos informais, associações e cooperativas. Do ponto de vista conceptual e promocional, não existe aqui um modelo de referência, mas ações variadas de apoio e incubação, por vezes identificadas com as novas "tecnologias sociais".

Esses dois âmbitos de análise empírica corresponderam a procedimentos específicos. A pesquisa sobre o microempreendedorismo individual foi realizada principalmente com base em fontes secundárias, tais como os levantamentos sobre micro e pequenas empresas, o perfil do microempreendedor e a economia informal, com destaque para os estudos do próprio SEBRAE e do IBGE. Um estudo sistemático em fontes primárias foi realizado em documentos e em material audiovisual do SEBRAE, alguns de natureza institucional e outros divulgados em sua órbita, para fins de difusão do modelo e de orientação didático-pedagógica para seus instrutores e seu público-alvo. Esses estudos tiveram por fim apreender a realidade das MPE e dos empreendedores de pequeno porte, analisar a concepção predominante nesse campo e, tanto quanto possível, inferir elementos teórico-conceituais válidos para uma compreensão do microempreendedorismo adequada à realidade dos setores populares, segundo uma perspectiva de fortalecimento e de superação de seus condicionantes estruturais.

No âmbito dos empreendimentos associativos, a investigação apoiou-se em fontes secundárias e primárias: as primeiras, disponibilizadas pelo SIES $^{2}$ (Sistema Nacional de Informações sobre a Economia Solidária), no qual se encontram os dados do Mapeamento; as segundas, através da pesquisa qualitativa em empreendimentos selecionados em três regiões distintas do Estado do Rio Grande do Sul, em segmentos econômicos e em formas de organização típicos

2 O SIES constitui uma das principais ações da Secretaria Nacional de Economia Solidária (SENAES/MTE). Compreende processos sistemáticos de coleta, tabulação e disponibilização de informações (www.sies.mte.gov.br) sobre os Empreendimentos de Economia Solidária, as Organizações de Apoio e Fomento e as Políticas Públicas existentes nesse campo. O primeiro mapeamento nacional foi realizado entre 2005 e 2007; o segundo deve concluir-se no início de 2011. 
da Economia Solidária. Através de visitas à região Central do Estado (Santa Maria), da Produção (Passo Fundo) e Metropolitana (Porto Alegre), dez empreendimentos foram examinados. Não obstante o número restrito de casos, a vantagem dessa opção residiu no fato de se tratarem de experiências já examinadas em pesquisas qualitativas anteriores (1993, 1997 e 2001), sobre as quais se dispunha de um acervo considerável de informações e, portanto, da possibilidade de comparar dados ao longo do tempo, lançando mão de uma perspectiva de análise longitudinal. Entre os dez empreendimentos, urbanos e rurais, contam-se grupos informais, associações e cooperativas, com atividades econômicas principais nos setores de produção agroecológica, comercialização, reciclagem, alimentação, confecções e artesanato. Análises comparativas mais amplas foram propiciadas pelo rol de 48 iniciativas pesquisadas anteriormente, com propósitos e metodologia semelhantes (GAIGER et al., 1999; GAIGER, 2006).

A pesquisa de campo teve como objetivos identificar as situações de adoção de formatos coletivos e seus respectivos graus de desenvolvimento e, de outra parte, avaliar os fatores individuais subjacentes a tais formatos, mensurando diante deles o diferencial representado pela gestão coletiva e pela cooperação econômica. Dessa forma, buscou-se discernir os vetores constitutivos do microempreendedorismo associativo, em vista das questões de fundo problematizadas pelo projeto de pesquisa.

Em resultado das investigações precedentes sobre o tema, teve-se como ponto de partida que os empreendimentos associativos se valem - ou se podem valer - de dinâmicas de gestão potencialmente privilegiadas para o desenvolvimento do empreendedorismo, assentes na cooperação no trabalho, em decisões coletivas, no compartilhamento de conhecimentos e na confiança em um projeto comum; portanto, em seus ativos supraindividuais e relacionais. Por outro lado, para serem funcionais, essas particularidades precisam ser conjugadas a uma gestão estratégica, fundamentada em conhecimento e em ferramentas adequadas às diferentes dimensões da organização coletiva, irredutíveis ao plano econômico e à racionalidade determinada pelo interesse próprio.

Dessa linha de argumentação decorre inevitavelmente um questionamento fulcral ao conceito paradigmático de "empreende- 
dorismo de oportunidade" (SCHUMPETER, 2006). Com efeito, em sua raiz tais investigações sobre as relações entre o empreendedorismo de pequena escala e o associativismo têm como propósito proceder a uma revisão crítica sobre o tema. Não obstante, foge à sua intenção enveredar por um padrão único de êxito na ação empreendedora, inteiramente contraposto ao modelo dominante. Mais vale sublinhar os aspectos da gestão empreendedora que incorporam a crítica aos limites e distorções do modelo convencional, respeitando, outrossim, aqueles fundamentos ou diretivas em acordo com as condições sociais em que o ato de empreender se materializa. Como se pondera, em conclusão de um amplo estudo sobre o microempreendedorismo realizado em Portugal:

Mais do que seria legítimo admitir, parece haver quadros [da administração pública] que ignoram, ou aparentam ignorar, os estudos que sustentam que o empreendedorismo, enquanto traço comportamental dos indivíduos, é contingente, no duplo sentido em que não se trata de um "gene" ou qualidade inata duradoura e em que se restringe a certas actividades e a algumas fases da vida pessoal. Ou seja, o que é preciso não é tanto um perfil empreendedor, mas muito mais, por exemplo, equidade no trato dos pré-empresários (isto é, acabar com os casos concretos de dois pesos e duas medidas) e muito mais acção e obras. (...) Trata-se de apurar protótipos de inovação social, tais como mecanismos de transição entre culturas de grupo distintas (da informal à formal e da académica à empresarial; da cultura de gestão comum à da de inovação, pelo menos a melhoria incremental permanente), bem como polir regimes alternativos de apoio a projectos empresariais, designadamente para gente na mó de baixo da azenha social. (PORTELLA et al., 2008, p. 243).

Assim, reconhecer a existência de padrões de empreendedorismo que não compartilham os atributos do modelo típico não implica a análise em separado dessas realidades. Convém, preferencialmente, tratá-las como processos interligados suscetíveis de conduzir a variantes ou a outros modelos, o ponto de interesse consistindo em examinar as razões desses afastamentos e aproximações, bem como seus efeitos sobre as iniciativas de pequeno porte.

O empreendedorismo tem sido tematizado por uma vasta literatura. Convém por isso esclarecer que esse texto não pretende 
escrutinar as visões predominantes e suas principais derivações, contendo nesse sentido apenas remissões pontuais a alguns autores de referência ${ }^{3}$. Mesmo entre as principais correntes teóricas, não há uma definição simples e isenta de controvérsias, tampouco é possível inferir uma concepção una, pois a assimilação das obras precursoras ocorreu conforme pressupostos distintos dos seus continuadores, inclusive sua definição de "economia". Ademais, houve um alargamento gradativo do conceito, extrapolando o campo econômico para a área social, política e institucional, nas quais o empreendedorismo veio a designar o exercício de um papel motor na implantação de projetos de interesse comum ou na reconfiguração das instituições (FERREIRA, 2005).

Da mesma forma, não se pretende adentrar os aspectos empíricos e metodológicos da pesquisa antes mencionada e dos estudos anteriores que confluíram para as tomadas de posição apresentadas a seguir. Os limites de espaço requerem um tratamento especialmente conciso quanto aos traços definidores do padrão convencional de empreendedorismo, provavelmente mais familiares ao leitor, mas igualmente quanto aos aspectos históricos e morfológicos dos empreendimentos associativos, alojados no interior do fenômeno mais recente da Economia Solidária, sobre o qual já existe uma farta literatura. Despojadas desses referentes, as ponderações sustentadas nesse artigo ficam diretamente endereçadas ao âmbito teórico e conceitual. Nesse plano específico, sintetizam os resultados das pesquisas empíricas já nomeadas e dos estudos bibliográficos correspondentes, focalizando, contudo, não as expressões concretas nas quais se traduzem as concepções e formas de promoção do empreendedorismo de pequeno porte, mas os axiomas e pressupostos situados em pano de fundo, de valor paradigmático.

Alguns resultados da pesquisa foram publicados (GAIGER, 2008, 2009) e outros se encontram em vias de sistematização. Elementos relevantes do aparelho conceitual vieram a público com

3 Quanto se tratar de uma tese ou conceito desenvolvido por tais autores em diversas publicações, apenas será feita alusão aos seus nomes. As obras mais diretamente relacionadas aos temas aqui desenvolvidos figuram na bibliografia e serão referidas em casos de citação literal ou menção a conteúdos específicos. 
a edição revista do Dicionário Internacional da Outra Economia (CATTANI et al., 2009). De acordo com os propósitos desse texto, esgrimem-se a seguir os principais contributos, ainda em processo de elaboração final no escopo do projeto, quanto às diferenças e relações entre os modelos de microempreendedorismo e quanto aos elementos basilares de um modelo alternativo.

\section{Contrapontos ao modelo convencional de micro- empreendedorismo}

O modelo adotado e propagado pelo SEBRAE apóia-se em um conjunto de premissas, praticamente onipresentes em seus documentos institucionais e nos estudos que as adotam e procuram, a partir dessa axiomática, analisar a realidade dos pequenos empreendedores e compreender suas carências e necessidades. Resumindo tais pressupostos, que definem as características fundamentais do autêntico empreendedor, tem-se:

Um indivíduo de personalidade e talento que preenche um padrão determinado de conduta econômica, o que lhe confere sucesso, prestígio e chances crescentes de novas realizações;

Como suas características superiores, destacam-se a capacidade de perceber oportunidades de negócios que outros (ainda) não percebem e de inovar, tomando a dianteira em uma ou várias frentes;

Além de senso de iniciativa, o empreendedor corre riscos calculados, cobra eficiência e qualidade, mostra persistência e comprometimento, é devotado ao trabalho, dispõe de uma rede de contatos, planeja e estabelece metas, é persuasivo, autoconfiante e independente;

Por fim, maneja essas virtudes otimizando as suas escolhas racionalmente e maximizando a sua utilidade individual.

Uma objeção primordial a essa linha de entendimento e de expectativa, em relação às virtudes e aos benefícios do empreendedorismo, tem a ver com o que se poderia considerar um equívoco de interpretação - embora dificilmente justificável - quanto ao que tinha em mente J. Schumpeter, cujas formulações cumprem um papel de referência mor, explícita ou implicitamente. Ao se referir a tais 
qualidades e empregar semelhante vocabulário, esse autor não tinha em vista algum tipo de padrão de conduta que se pudesse difundir e replicar entre os agentes econômicos, mas exatamente o seu oposto. O empreendedor, que Schumpeter se preocupou em diferenciar do capitalista ordinário, representa um acontecimento excepcional e passageiro, no tocante aos indivíduos que o encarnam e às suas circunstâncias, das quais depende a eventual existência de oportunidades a serem exploradas. Sua ação, quando bem sucedida, gera ondas seletivas de prosperidade (para quem inicia ou se posiciona o quanto antes na vanguarda das inovações) e ondas sucessivas de obsolescência e depressão (para os demais), com isso imprimindo um ciclo qualitativamente novo ao desenvolvimento capitalista.

Ironicamente, ao pronunciar-se sobre os fatores conducentes ao declínio definitivo do capitalismo, Schumpeter enumera, entre outros, o desaparecimento do empresário inovador e a eliminação progressiva das pequenas empresas. O primeiro, ao ser substituído pelos departamentos de $\mathrm{P} \& \mathrm{D}$, que terminariam por socializar as chaves da inovação produtiva. A segunda tendência reduziria o número de defensores da propriedade privada, contra formas mais impessoais de propriedade dos meios de produção. Por conseguinte, ainda que se possa imaginar a aplicabilidade do modelo clássico de empreendedorismo a determinadas condições do capitalismo contemporâneo, como as empresas de alta densidade tecnológica, como fazê-lo para o universo infinitamente maior das pequenas empresas, que necessitam de equilíbrio e estabilidade diante dos riscos inevitáveis dos seus negócios, e não obstante estejam, para Schumpeter, fadadas ao desaparecimento? A imagem épica inspirada pela instigante elaboração deste autor decididamente não serve como tipo-ideal quando se tem em vista a realidade cotidiana da economia, mas tampouco como ideal, como tem sido correntemente utilizada, ao preço de uma constante confusão entre lenda, mito e realidade (BOUTILLIER \& UZUNIDIS, 1999).

Não surpreende que, embora se apresente discursivamente associada a um espírito otimista, confiante em seus resultados, a concepção canônica do microempreendedorismo ressinta-se não apenas de exemplos convincentes quanto à sua eficiência, isto é, que transcendam os casos individuais de êxito e demonstrem que 
a ação empreendedora produz altos níveis de impacto e efeitos multiplicadores. Há pontos nevrálgicos no plano axiomático e naquele de suas aplicações à realidade de seu público alvo, nem exclusivamente econômica, nem apenas governada por princípios utilitaristas. Resumamos tais problemas em oito pontos:

O modelo contém uma exigência notoriamente elevada, dado o conjunto de atributos requeridos do empreendedor: o mesmo deve possuir uma plêiade excepcional de virtudes, apanágio de indivíduos talentosos e intimoratos, saudados repetidamente pela literatura, por vezes em obras de teor notoriamente hagiográfico. Ao revestir-se de um caráter incomum, a capacidade de empreender torna-se dificilmente transferível a outrem pelo aprendizado e, portanto, não é multiplicável, senão no intuito conformista de produzir réplicas imperfeitas cujo insucesso, praticamente inevitável, termina por validar o modelo ideal.

Uma contradição lógica, insuperável no quadro da racionalidade competitiva intrínseca ao modelo, se introduz: se um número razoável de agentes econômicos adquire tais qualificativos de distinção, como se pretende, tais diferenças fatalmente se anulam, cedo ou tarde. Embora seja apregoado para todos, o modelo apenas pode funcionar se funcionar apenas para alguns. Mesmo para estes, os ganhos são transitórios, em razão da progressiva saturação do mercado provocada pela difusão das inovações. Ademais, adotar uma lógica estrita ou majoritariamente competitiva implica o risco de minar as relações sociais que sustentam as atividades econômicas dos agentes presentemente na vanguarda, em particular quando tais relações possuem componentes não utilitários e se inserem em lógicas da reciprocidade, nada incomuns entre os setores populares (KRAYCHETE, 2000).

Com tais requisitos, e ao apontar para "janelas de oportunidades" que logo se fecham, o empreendedorismo passa a ser invariavelmente - e involuntariamente - um fenômeno efêmero, de efeitos transitórios. Embora perfeitamente de acordo com Schumpeter, o fato se choca com a idéia de que empreender seja uma possante alavanca propulsora de contínuo desenvolvimento econômico. A natureza momentosa da ação empreendedora contrapõe-se ao mister de compatibilizar os requisitos de eficiência da organização 
empreendedora e de sua sustentabilidade, por meio de externalidades positivas duradouras.

Por um lado, a premissa da inovação destrutiva, ao se manifestar na prática, acarreta efeitos sistêmicos diferenciados, de provável sentido negativo ou mesmo regressivo em alguns casos. O desequilíbrio inerente ao sistema capitalista, no qual se criam brechas para a inovação, é acentuado a níveis críticos em contextos de empreendedorismo (schumpeteriano), o que gera ganhos e perdas seletivamente, sem nenhuma garantia de que tais efeitos se compensem mutuamente. Por outro lado, a premissa da mudança, reflexo típico da ação empreendedora, supõe conjunturas específicas para seu advento, contando com nós górdios de esgotamento das combinações tecnológicas até então empregadas, o que não constitui a realidade normal, geral e, mesmo, desejada de economia.

O modelo paradigmático superior de empreendedorismo de oportunidade (aquele que, movido pela descoberta de um nicho de mercado, pelo senso de iniciativa e pela busca de sucesso, traz maiores benefícios à sociedade) encontra-se encerrado no interior da lógica de ação individual e em sua racionalidade instrumental conexa, tendo como motivação o ganho pessoal (sob forma de enriquecimento, prestígio, etc.). Não se observam questionamentos quanto à premissa utilitarista de que a busca "egoísta" de maior satisfação gera o maior bem-estar para a coletividade, um argumento discutível do ponto de vista lógico e em larga contradição com os fatos ${ }^{4}$.

Nas economias contemporâneas, as organizações econômicas em que se pode desenvolver algum tipo de ação empreendedora possuem via de regra dimensões diminutas, estando desprovidas dos requisitos típicos do oportunismo empreendedor. Tal realidade, em que predominam as pequenas empresas e os negócios informais, demanda o emprego de outros enfoques e conceitos, como o de economia popular, que remetem à percepção de lógicas direcionadas à reprodução da vida (CORAGGIO, 1999; 2007), diante da qual a cisão entre considerações de natureza econômica e imperativos extra-econômicos, subordinando-se os segundas às primeiras, não faz sentido.

4 A esse respeito, ver as importantes elaborações do M.A.U.S.S - Mouvement Antiutilitariste des Sciences Sociales, especialmente os trabalhos de Alain Caillé. 
De um ponto de vista mais geral, o foco no comportamento utilitário individual, sem menção às posições sociais distintas, incita a ignorar a dimensão conflitual, excludente e via de regra predatória da economia, em particular da economia concorrencial capitalista, bem como o fato de estar estruturada em relações de poder e em processos de dominação. Desse ponto de vista, a importância econômica e social da Informalidade contrasta com a enorme debilidade política dos pequenos empreendedores urbanos, a quem faltam identidade comum, unidade e mecanismos de representação. Já é outra a realidade da agricultura familiar, cuja organização de classe explica em boa medida as políticas direcionadas ao setor, pelas mesmas razões já em desenvolvimento para atender as demandas da Economia Solidária.

As expectativas depositadas no empreendedorismo não se coadunam com a realidade dos países desenvolvidos, nos quais as pesquisas do GEM (Global Entrepreneurship Monitor), com certeza as mais sistemáticas e abrangentes, apontam índices menores de ação empreendedora. Tampouco são coerentes com os dados levantados nos países periféricos, cujas taxas mais elevadas de empreendedorismo contrastam com a ausência dos efeitos benéficos que deveriam produzir: os países menos inovadores são os mais empreendedores; embora evidenciem os maiores índices de empreendedorismo, são também os mais pobres ${ }^{5}$.

A dor ensina a gemer e o hábito faz o monge: pode-se imaginar que o alto nível de empreendedorismo em países menos desenvolvidos seja precisamente reflexo das menores facilidades institucionais oferecidas à ação empresarial. Não será contrapartida da alta volatilidade dos negócios e das empresas ou da incapacidade de absorção da força de trabalho pelo mercado formal de trabalho? Em outros termos, e por hipótese, isso seria sintoma de um ethos econômico (GAIGER, 1997) forjado pela necessidade de virar-se por conta, que instila e com o tempo sedimenta uma predisposição à ação econômica independente, ainda que incapaz de surtir resultados significativos?

5 Em benefício da dúvida, os dados do GEM que apontam percentuais elevados de empreendedorismo em certos países não se apresentam apoiados em indicadores claros e convincentes, ademais de serem contraditórios com os dados mais gerais sobre as MPE, ao menos no Brasil. 
A dúvida anterior perdura porque o empreendedorismo de necessidade (determinado pela falta de outras alternativas de ocupação e renda, não por afinidade e pela assunção deliberada ao risco), ao ser relegado a uma posição marginal e complementar - quando muito uma etapa de transição ao autêntico empreendedorismo - é pouco estudado e palidamente compreendido, salvo exceções, que ainda assim não abrem mão do modelo de referência (CIMADON, 2008). Esse tratamento depreciativo ocorre a expensas da racionalidade própria dos setores vinculados à economia informal ou à economia popular, determinada pelas condições e pelas margens de escolha com que lidam tais agentes econômicos. Em ambientes altamente desfavoráveis, a criatividade e a habilidade em improvisar podem ser indicadores de empreendedorismo adequados e mais relevantes do que a assunção do risco, da mesma forma que garantir a sobrevivência pode representar um desafio da maior magnitude (HESPANHA, 2009). Ademais, muitos indivíduos atingidos por necessidades prementes não empreendem. Por conseguinte, o ato de empreender, nessas condições, resulta de uma combinação de fatores, não apenas de um estado de carência e de inaptidão à ação econômica movida pela oportunidade.

A dicotomia entre empreendedorismo de oportunidade e de necessidade desconhece os tipos intermediários, híbridos, cuja existência é altamente presumível pelo simples fato de que as duas situações não são incompatíveis e podem manifestar situações momentâneas, intercambiáveis, antes do que um estilo definitivo de ação econômica.

A rigor, observa-se aqui uma flutuação conceitual: os atributos do empreendedor de oportunidade, evocados no plano teórico e doutrinário enfaticamente, dentro de um paradigma de indivíduoempresa, correspondem fortemente à matriz schumpteriana. No momento de avaliar as situações concretas, o conceito é abrandado e praticamente se dilui. Nas pesquisas de referência do GEM, chega-se ao ponto de identificá-lo com a simples existência de uma intenção, por parte do indivíduo, de criar uma empresa econômica com fins de lucro, sem maiores considerações sobre as características efetivas que dito empreendimento possui ou virá a assumir. 
A ação focalizada no empreendedorismo de oportunidade, premeditadamente ou não, termina restrita a uma minoria de empreendedores potenciais. Ou se trata de um "trabalho de Penélope", condenado a perpetuar-se sem produzir senão resultados simbólicos de impacto restrito, ou se utiliza um modelo idealizado na expectativa questionável de que sua promoção exemplar venha a semear uma cultura empreendedora vicejante, capaz de superar os obstáculos diretos e indiretos que atingem a maioria dos agentes econômicos de pequeno porte.

Nesse aspecto, cumpre assinalar lacunas evidentes no Brasil para uma avaliação conclusiva: os balanços das MPE e da economia informal não consideram a presença da componente empreendedora como fator do grau de êxito ou de insucesso dos negócios. Por sua vez, o SEBRAE parece ter nas pesquisas do GEM sua base principal, quase exclusiva, de avaliação do empreendedorismo; no entanto, tais pesquisas não focalizam as empresas, mas sim os indivíduos, sendo ainda genéricas, sem relação com as iniciativas efetivamente promovidas. Nos poucos casos em que se podem estabelecer algumas correlações (Vox Populi, 2007), os fatos não são a princípio abonadores: a procura pelo apoio do SEBRAE não parece reduzir as chances de extinção das MPE, que por outro lado cogitam a participação em redes e a formação de cooperativas como saídas. Mais importante, do conjunto dos dados da mesma pesquisa, se depreende que as MPE elegem mais os aspectos básicos da gestão (contabilidade, informações mínimas sobre mercado, crédito), além das relações humanas, e menos os aspectos típicos do modelo empreendedor (liderança, tecnologia, assunção de riscos) como decisivos para impedir sua crise e garantir seu crescimento.

Por fim, a focalização no indivíduo e nos seus atributos pessoais, com menções apenas ocasionais aos aspectos relacionais e às vantagens da associação entre os pequenos empreendedores, impede a tematização dessas outras possibilidades e de suas características específicas. Acontece, aqui, mais um caso de "desperdício de experiências" (SANTOS, 1999), que acomete igualmente a produção acadêmica de disciplinas como a Sociologia, orientada por um largo período pela mesma perspectiva dos promotores do 
empreendedorismo (supply-side perspective), que acentua os traços individuais dos agentes econômicos (THORTON, 1999).

A literatura canônica admite que um fator-chave do empreendedorismo nas organizações é a mobilização e multiplicação dos recursos humanos que a integram, o que implica formar e disseminar competências, além de gerar adesão para as metas da empresa. Isto demanda uma capacidade de formar uma cultura ou um ethos empreendedor, através de uma ação sistemática e contínua que envolve primordialmente o plano relacional e a cooperação mútua. No entanto, as características organizacionais supra-individuais, presentes em qualquer empresa econômica e altamente definidoras da sua natureza, passam ao largo de maiores considerações, o que poderia explicar o silêncio acerca das formas associativas que tais organizações eventualmente assumem, de modo explícito ou latente. Tais aspectos relacionais tendem a ficar em plano secundário apenas quando se observam os pequenos negócios superficialmente, uma vez que ocupam em geral uma ou duas pessoas, responsáveis em primeira linha pelo negócio. Não poderiam ficar desconhecidos por análises atentas às dinâmicas não imediatamente aparentes e ao fato de que as organizações econômicas populares, individuais, familiares ou coletivas, não se resumem ao agir estritamente econômico das empresas privadas com ânimo de lucro, estendendo sua malha de relações além dessa esfera.

\section{Contribuições dos empreendimentos associativos}

Uma das novidades promissoras da Economia Solidária reside em suas possibilidades de superar o padrão de subordinação e de vulnerabilidade das formas típicas de economia dos setores populares, como as ocupações por conta própria, as microempresas e a agricultura de subsistência. Para cumprir essa expectativa, lhe tem sido necessário vencer questões e tarefas propriamente econômicas. No entanto, esses experimentos associativos de produção de bens e de serviços têm merecido uma atenção pouca expressiva dos programas públicos e de organizações civis dedicadas à promoção do empreendedorismo. Salvo exceções recentes, ficam relegados a uma posição secundária e subalterna 
nas políticas voltadas ao empreendedorismo de pequeno porte e na compreensão vigente a respeito ${ }^{6}$.

Para agravar o quadro, ao se transitar do universo das MPE e entrar de pleno naquele da Economia Solidária e demais alternativas às formas de produção capitalista, nota-se no ambiente intelectual que lhes é peculiar uma resistência ao emprego de termos como empresa, eficiência e empreendedorismo e à própria discussão sobre a economia. A promoção dos empreendimentos econômicos solidários, viável apenas quando conduzida em termos realistas, experimenta tensões permanentes provocadas por: a) uma lógica dualista, que contrapõe a totalidade capitalística à sua ainda inexistente antítese, retrocedendo então para um monismo paralisante ("hoje, tudo é capitalismo") que impede avanços no sentido de uma percepção plural e dialética da economia e das estruturas sociais; b) uma teleologia adventista, de expectativa de construção de uma realidade "totalmente outra", que provoca constantes refrações no entendimento e fortalecimento da práxis popular. Assim, a promoção dessas práticas econômicas, manifesta ou potencialmente alternativas, não obstante envolva um número crescente de organizações civis e de programas públicos, sofre amiúde com a resistência em abordar insofismáveis tarefas econômicas e, sobretudo, com a ausência de formulações conceituais substitutivas (GAIGER, 2008).

Ora, o termo empreendedorismo, em primeira mão, evoca a capacidade de tocar à frente uma organização econômica, de administrá-la e conduzi-la. Essa capacidade não é inata e cada vez menos tem sido possível adquiri-la a contento espontaneamente, apenas pela prática. No entanto, mesmo na falta de sistematizações a prática ensina e incide sobre o plano das formulações. Cumpre, portanto, indagar como se pode desenvolvê-la à luz das experiências observáveis na Economia Solidária, tendo em vista as condições ge-

6 Geralmente, as iniciativas de apoio aos formatos associativos ou se restringem às organizações maiores, notoriamente as grandes e médias cooperativas, ou desconsideram as especificidades essenciais desses empreendimentos e os tratam como empresas convencionais de capital privado. O SEBRAE, por seu turno, tem se aproximado do universo da Economia Solidária e firmado convênios de assessoria técnica, restando avaliar que efeitos isso poderá trazer à sua base conceitual e metodológica. 
rais da economia atual, com suas exigências cognitivas crescentes, e as condições particulares em que essa capacidade deve ser exercida pelas organizações baseadas na livre associação de trabalhadores.

Estudos e avaliações têm atestado a presença de dispositivos coletivos de iniciativa de trabalhadores, como associações, cooperativas e arranjos comunitários, em processos bem sucedidos de inserção em mercados (ABRAMOVAY et. al., 2003) ou de fortalecimento de economias locais (PARREIRAS, 2007). A Economia Solidária, que agrega uma parcela dessas iniciativas, não é um caso tão à parte quanto parece. Sua contribuição mais importante, para o debate sobre o microempreendedorismo, consiste em trazer à luz alguns elementos latentes, mas fundamentais, da natureza e da lógica que presidem o comportamento geral - irredutível ao utilitarismo e a seus corolários - por parte dos trabalhadores que empreendem e das diversas expressões econômicas dos setores populares. As aquisições de que dispomos, a partir das pesquisas empíricas e da revisão de literatura, embora nem indubitáveis nem definitivas, podem ser resumidas inicialmente nas seguintes considerações:

Empreender, para os indivíduos comuns mortais que se esmeram em tocar à frente seus pequenos negócios, não pode senão evocar a capacidade de liderar e promover mudanças gradativas nas atividades econômicas tradicionais (ABRAMOVAY et al., 2003), praticadas e conhecidas, por meio de mutações sucessivas e progressivas que exploram os ativos disponíveis e ensejam melhorias graduais na inserção dos agentes econômicos nos diferentes mercados aos quais têm acesso. Trata-se de um processo de metamorfose (GAIGER, 1994; GAIGER et al., 1999), não de criação destrutiva.

As políticas de apoio aos pequenos negócios, formalizados ou não, produzem resultados quando o seu público, no lugar de "alvo", é estimulado a ser sujeito da construção de novos ambientes localizados em que as iniciativas singulares sejam favorecidas, reforçando os laços de confiança e reduzindo os "custos de transação" que afetam os ambientes de desconfiança. O foco de tais políticas deveria ser o incremento da capacidade própria de geração de renda dos pobres (ABRAMOVAY et al., 2003; SEM, 2001), ou seja, de seu protagonismo econômico. 
Nas ações de promoção, seria fundamental entender as MPE e a informalidade não apenas e não principalmente como sinais de um estado de carências, mas como expressões ou extensões das "unidades domésticas" (CORAGGIO, 1999), nas quais o objetivo de acumulação é condicionado àquele de manter e melhorar a qualidade de vida. Sendo assim, a lógica que as movimenta é inseparável de postulados de valor: em linguagem weberiana, a racionalidade material precede a racionalidade instrumental.

Ampliando ou subvertendo os conceitos canônicos, caberia rever aspectos constitutivos da ação empreendedora. De um lado, valorizando a inovação como um ato de criatividade, que comporta em muitos casos - especialmente nas condições atípicas (embora, predominantes) da economia dos pobres - a arte do improviso, apoiada em saberes tácitos cevados pela experiência. De outro lado, compreendendo a aversão ao risco, signo por excelência da falta de espírito empreendedor, como algo que pode decorrer de decisões ponderadas, de uma prudência recomendável no exercício da gestão em ambientes de grande incerteza. Uma situação habitual das MPE, onde importa via de regra preservar o controle sobre os fatores essenciais ao êxito ou à sobrevivência da organização.

Dito isto, avançar na direção de um modelo alternativo de empreendedorismo, especialmente no âmbito da Economia Solidária, demandaria ter em vista ao menos cinco exigências:

Superar a razão dualista, que se compraz em opor o sistema existente à sua presumida antítese, concebida em termos antagônicos. Implica reconhecer que a ciência econômica, como qualquer outra, não é uma simples expressão da visão e dos interesses dominantes, mas reflete - assimetricamente, é verdade - a multiplicidade da experiência humana e a diversidade de orientações presentes nas formas praticadas e nos modelos prescritivos da economia. O que se percebe tanto nas contendas entre os economistas quanto nas visões sobre a economia provenientes de outras disciplinas, como é o caso notório da Sociologia Econômica.

Entender que o agir econômico, quando não meramente circunstancial, exige algum conhecimento específico e um manejo consciente dos elementos com ele relacionados. Isto vale sobremaneira para toda atividade coordenada que envolve um conjunto 
de pessoas e de recursos materiais e financeiros, cujo acionamento implica fazer escolhas, traçar objetivos, prever passos, negociar interesses e viabilizar acordos.

Como já apontado anteriormente (GAIGER, 2008), o nó crucial de muitos empreendimentos de Economia Solidária não reside no fato de que antes os seus integrantes estivessem inteiramente despojados de experiência econômica e de saberes. Sim, no fato de que tais ativos em geral não servem adequadamente para atender aos requisitos de um empreendimento associativo e cooperativo, caracterizado por relações de equidade entre os seus membros. Não servem tampouco para que esses empreendimentos garantam melhorias consistentes na inserção dos trabalhadores pobres no mercado, pois isso significa driblar redes e estruturas muito bem implantadas de dominação econômica e política que pesam sobre eles.

Considerar que, no contexto dos empreendimentos associativos, empreender equivale primordialmente a respeitar as características e (com isso) explorar as virtudes da comunidade de trabalho (GAIGER, 2006), núcleo vital dos empreendimentos, potencializando as forças geradas pela união dos membros. Dessa forma, fundamentalmente, é possível conduzir a organização e a gestão dos fatores produtivos, humanos e materiais, com vistas à realização das suas metas. Em outros termos, a natureza associativa e cooperativa dos empreendimentos é suscetível de gerar uma série de efeitos positivos ou de economias potenciais (RAZETO, 1990; 1993), que engendram um círculo virtuoso a ser reconhecido e explorado. A união e a inteligência coletiva dos trabalhadores são mobilizáveis como recursos fundamentais para que os empreendimentos lidem com a realidade contingente e logrem sua sobrevivência.

Compreender tanto a economia na qual estão imersos os empreendimentos quanto a economia que pretendem e podem efetivamente praticar. Para que os empreendimentos realizem suas metas, não basta a seus integrantes serem solidários, almejarem e praticarem o bem comum. Não é tampouco suficiente ter líderes carismáticos, capazes de agregar e unir as pessoas, ou líderes democráticos, que respeitam os pontos de vista individuais e estimulam a participação. Da mesma forma, não basta ao empreendimento atuar em movimentos sociais, participar de fóruns ou tomar parte de redes solidárias, 
em nome do avanço político da Economia Solidária. Essas iniciativas não eliminam nem resolvem os problemas econômicos, o que requer, nas circunstâncias da maior parte dos empreendimentos:

Desenvolver uma gestão pró-ativa: superar o estilo baseado essencialmente na capacidade de adaptações sucessivas a circunstâncias que se apresentam como fatos determinantes, sobre os quais não se possui nenhum controle ou poder de reação, senão em termos defensivos (BOURDIEU, 1963; 1977);

Compreender a complexidade da organização e sua irredutibilidade à soma das realidades individuais: distinguir a realidade tangível dos indivíduos e famílias que integram o empreendimento - com suas demandas muitas vezes prementes e justificadoras de uma atitude imediatista - da realidade da empresa em si - com seus tempos e rotinas próprias, suas margens de escolha e sua incontornável necessidade de planejamento;

Considerar o trabalho como uma realidade primordial, ou como fator organizador (RAZETO, 1990) dos empreendimentos associativos, pois neles ocupa uma posição estruturalmente central, por três razões essenciais: a) é o principal recurso produtivo, físico e intelectual, ao dispor dos empreendimentos; b) está na raiz e constitui a razão de ser ineludível dos empreendimentos; c) esse recurso produtivo e esse marco original e motivacional são encarnados virtualmente pelo corpo social do empreendimento, o que converte a participação ampla e equitativa nas decisões em algo natural nessa nova realidade (GAIGER, 2001; 2006).

Perceber a enorme distância existente entre essa situação e a realidade habitual de gestão das empresas privadas, na qual os trabalhadores não detêm posições de comando, prerrogativa em última instância do poder acionário. Por serem organizações econômicas, os empreendimentos associativos necessitam de empreendedorismo; por serem intentos alternativos, precisam inovar nesse campo através de um estilo de empreendedorismo próprio, de caráter participativo e democrático.

Essas últimas afirmações afastam-se em pontos essenciais da concepção canônica de empreendedorismo. Não obstante, alguns dos elementos enfatizados por essa última, devidamente contextualizados, mantêm-se pertinentes. A título de exemplo, como enfatiza 
Razeto (1990, p. 50), para que possam funcionar como categoria organizadora, os trabalhadores precisam apresentar um espírito de empresa, através da: a) disposição a assumir os riscos implicados nas estratégias e nas atividades do empreendimento; b) determinação ou vontade de atingir os objetivos propostos, tendo prazer e satisfação em vencer obstáculos; c) autoconfiança, independência pessoal e iniciativa. Necessitam ainda dispor de certa capacidade de formular prognósticos, indispensáveis ao planejamento de médio e longo prazo e a correções de rota provocadas por circunstâncias favoráveis ou adversas.

Convém salientar que a boa administração de um empreendimento econômico, embora cada vez mais se apóie em conhecimento profissional especializado, não é mera questão de competência científica, mas de habilidade em lidar com problemas diários os mais variados, a exigir tarimba e liderança. Se as experiências de cada sócio se somam, é de se esperar que propiciem maior acerto nas decisões e maior legitimidade para os responsáveis por sua execução. Quando falta a competência específica ao ramo de negócios escolhido, ela é construída ao longo da vida prática do empreendimento, analogamente ao que ocorre com a empresa capitalista. Nesta, o aprendizado se limita principalmente aos integrantes do corpo de executivos, ao passo que, naquele, pode estender-se a todos os membros. (SINGER, 2000, p. 22).

\section{Por um enfoque inovador}

Uma das conclusões quase triviais dos estudos sobre o empreendedorismo é de que inexistem modelos, fórmulas ou receitas prontas. É característica do empreendedorismo a multiplicidade das suas expressões concretas, em boa medida definidas em função das circunstâncias. Mesmo os exemplos mais bem sucedidos são replicáveis apenas com engenho, exigindo então novas doses de senso estratégico e de sagacidade, sempre em função do peso decisivo do contexto envolvente. De outra parte, o empreendedorismo em seu sentido mais estrito afasta-se da gestão hodierna e reveste-se de um caráter extraordinário, pontual, fadado a um curto ciclo de existência, o que implica limites decisivos, já apontados. Seu sucesso altera 
automaticamente as condições que o tornaram possível e mina rapidamente seu poder de impacto, tanto mais se estiver intimamente vinculado ao fenômeno da inovação. $\mathrm{O}$ empreendedorismo clássico é ao mesmo tempo contingente, único e efêmero. Sua conversão em condutas de amplo alcance e em políticas de longo prazo requer uma mudança de enfoque, aqui sintetizada em seis proposições:

Adotar preferivelmente uma acepção branda de empreendedorismo, ao alcance de indivíduos e organizações desprovidas daquelas condições tão singulares, mas ainda assim capazes de agir com intuição, iniciativa, arrojo e criatividade. No lugar de posicionar o indivíduo singular, atomizado pela teoria neoclássica como fonte da ação, e não apenas como fonte de análise (tal como procedeu Schumpeter), conviria entender o empreendedorismo como uma prática social: "uma sequência de comportamentos variáveis ao longo do tempo e orientados para a organização dos fatores de produção numa data unidade econômica. Comportamentos individuais e coletivos." (PORTELA et al., 2008, p.29). Em primeiro lugar, para aproximar a análise da realidade do mundo econômico em geral e da realidade particular das micro e pequenas empresas e dos empreendimentos populares. Em segundo lugar, a fim de tomar dita realidade como um campo de ensaios, sujeito a disputas e alianças entre os atores econômicos, a ser compreendido mediante uma crítica do paradigma da inovação destrutiva. Essa opção admite que a ação empreendedora exemplar é susceptível de produzir lições e modelos ao menos parcialmente dissemináveis, sem contanto exigir condições excepcionais ou provocar a eliminação certa dos agentes econômicos incapazes de aproveitar a "janela de oportunidades" momentaneamente aberta.

Considerar que o empreendedorismo depende de fatores contextuais, de nível meso e macro, cuja natureza é não somente econômica, mas igualmente política e ideológica. Empreender significa ter consciência de tais externalidades e lidar com elas, tirando proveito no sentido de afastar os elementos de risco e de carrear recursos para a organização. Por essa razão, as políticas de apoio ao empreendedorismo dos pobres apresentam impacto muito mais rápido e sustentável quando articuladas a formas de organização social dos próprios empreendedores nas quais esses 
atuam como sujeitos políticos (ABRAMOVAY et. al., 2003; GAIGER, 2009). Tal reto supõe trabalhar para a formação de uma identidade aglutinadora e pela superação das estruturas sociais de dominação que pesam sobre os pobres. Desse ponto de vista, é necessário politizar o empreendedorismo, vendo-o como elemento de luta social comportando dimensões emancipatórias.

Os dois padrões de empreendedorismo, de oportunidade e de necessidade, na visão predominante são concebidos como altamente determinantes dos resultados do agir econômico, funcionando como pilares do modelo explicativo. Contudo, eles se viabilizam e se expressam em situações sociologicamente bastante distintas, não sendo, por conseguinte, simples questão de escolha, mas de condições de possibilidades (BOURDIEU, 1963). Seria mais razoável inverter a cadeia causal, entendendo tais padrões como resultantes de um conjunto específico de condições prévias - materiais, intelectuais e sociais - que condicionam a ação econômica. Os padrões de empreendedorismo passariam à condição de variáveis-desfecho, o que altera profundamente a compreensão do problema e a metodologia de promoção do empreendedorismo.

Destronar a primazia da racionalidade competitiva imperante em ambientes de desconfiança, subjacente à visão clássica do empreendedorismo, combinando-a com modelos colaborativos favoráveis à experimentação e à descoberta em regime de riscos partilhados. Essa assertiva tem-se mostrado válida para o mundo das empresas em geral, não havendo motivos para descartá-la no caso dos empreendimentos associativos e dos empreendimentos populares. A propósito, as possibilidades de compatibilizar a perspectiva da inovação com aquela da cooperação em redes têm sido tratadas pela literatura recente (BALESTRIN \& VERSCHOORE, 2008; VALE, WILKINSON \& AMÂNCIO, 2008).

Compreender a inovação como um ato de criatividade a ser conferido em diferentes esferas, seja de ideias, de organização, de gestão ou de mercados (PORTLEA et al., 2008), todas vitais ao processo de metamorfose antes evocado, a partir do qual se constituem e se consolidam os experimentos associativos. A propósito, talvez a "arte do improviso" diante de desafios incessantes seja um dos principais trunfos dos empreendedores da Economia Solidária. Não 
como simples ação reativa, ditada pela força das circunstâncias, mas como exercício de um saber tácito adquirido ao longo do tempo, cada vez que as dificuldades superam os recursos ao alcance da mão e apelam ao despojamento e à inventividade.

Não tornar absoluto o princípio do risco assumido e centrar a análise no equilíbrio logrado entre risco e prudência, ou entre a inclinação e a aversão ponderada ao risco. A condução dessa tensão permanente é reveladora da capacidade de gestão em ambientes de incerteza, denotando o controle exercido sobre os condicionamentos essenciais ao êxito da organização. No caso das iniciativas de Economia Solidária, já se pôde constatar que a gestão austera e o cuidado em evitar manobras cujo insucesso resultaria em provável insolvência caracterizam os empreendimentos mais longevos e com margens minimamente razoáveis de investimento (GAIGER, 2009).

Por fim, cumpre manter o entendimento de que existem vários tipos de empreendedorismo. Do contrário, a perspectiva que classifica a grande maioria das pequenas experiências econômicas em um padrão marginal de empreendedorismo, das quais se espera a evolução para o padrão superior do empreendedor por oportunidade, seguirá impondo sua lógica, minando a emergências de outras possibilidades econômicas e promovendo uma utópica garantia de sucesso para todos, em franca contradição com a realidade.

Recebido em: 30.7.2010

Aprovado em: 12.9.2010

\section{Referências}

ABRAMOVAY, R. et al. Mercados do empreendedorismo de pequeno porte. Brasília: CEPAL, 2003.

BALESTRIN, A. \& VERSCHOORE, J. Redes de cooperação. Estratégias de gestão na nova economia. Porto Alegre: Bookman, 2008.

BOURDIEU, P. La société traditionnelle; attitude à l'égard du temps et conduite économique. Sociologie du Travail. Paris, v. 1, 1963.

BOURDIEU, P. Une classe objet. Actes des Recherches en Sciences Sociales. Paris, 1977. 
BOUTILLIER, S. \& UZUNIDIS, D. La légende de l'entrepreneur. Le capital social ou comment vient l'esprit d'entreprise. Paris: Syros, 1999.

CATTANI, D. et al. (Orgs.). Dicionário internacional da outra economia. Coimbra: Almedina, 2009.

CIMADON, J. Empreendedorismo em empresas criadas por necessidade. Santa Maria. Dissertação (Mestrado em Engenharia de Produção). Universidade Federal de Santa Maria, 2008.

CORAGGIO, J. Da economia dos setores populares à economia do trabalho. In: KRAYCHETE, G; LARA, F. \& COSTA, B. (Orgs.). Economia dos setores populares: entre a realidade e a utopia. Petrópolis: Vozes, 1999.

CORAGGIO, J. Una perspectiva alternativa para la economía social: de la economía popular a la economia del trabajo. In: CORAGGIO, J. (org.). La economía social desde la periferia: contribuciones latinoamericanas. Buenos Aires: Altamira, 2007.

FERREIRA, S. O que tem de especial o empreendedor social? O perfil de emprego do empresário social em Portugal. Coimbra: Centro de Estudos Sociais (Oficinas do CES, 223), 2005.

GAIGER, L. Sobrevivência e utopia: os projetos alternativos comunitários no RS. Cadernos CEDOPE, São Leopoldo, n. 10 (Série Movimentos Sociais e Cultura), 1994.

GAIGER, L. Ethos de posição e vida cotidiana. Estudos Leopoldenses, v. 33, n. 151, p. 69-94, 1997.

GAIGER, L. Virtudes do trabalho nos empreendimentos econômicos solidários. Revista Latinoamericana de Estudios del Trabajo, Buenos Aires, v. 7, n. 13, p. 191-211, 2001.

GAIGER, L. A racionalidade dos formatos produtivos autogestionários. Sociedade e Estado, Brasília, v. 21, n. 2, p. 513-545, 2006.

GAIGER, L. A dimensão empreendedora da economia solidária. Notas para um debate necessário. Revista Otra Economía, Buenos Aires, v. II, n. 3, p. 58-72, 2008.

GAIGER, L. A associação econômica dos pobres como via de combate às desigualdades. Caderno CRH, Salvador, v. 22, n. 57, p. 583-600, 2009. 
GAIGER, L. et al. A economia solidária no RS: viabilidade e perspectivas. Cadernos CEDOPE, São Leopoldo, n. 15 (Série Movimentos Sociais e Cultura), 1999.

HESPANHA, P. Microempreendedorismo. In: CATTANI, A. et al. (Orgs.). Dicionário internacional da outra economia. Coimbra: Almedina, 2009.

KRAYCHETE, G. Economia dos setores populares: entre a realidade a utopia. In: KRAYCHETE, G; LARA, F. \& COSTA, B. (Orgs.). Economia dos setores populares: entre a realidade e a utopia. Petrópolis: Vozes, 1999.

PARREIRAS, L. Negócios solidários em cadeias produtivas: protagonismo coletivo e desenvolvimento sustentável. Rio de Janeiro: IPEA, 2007.

PORTELA, J. et al. Microempreendedorismo em Portugal: experiências e perspectivas. Lisboa: INSCOOP/GRECA Artes Gráficas, 2008.

RAZETO, L. Las empresas alternativas. Montevidéu: Editorial Nordan-Comunidad, 1990.

RAZETO, L. Economia de solidariedade e organização popular. In: GADOTTI, M. \& GUTIÈRREZ, F. (Orgs.). Educação comunitária e economia popular. São Paulo: Cortez, 1993.

SANTOS, B. S. Porque é tão difícil construir uma teoria crítica? Revista Crítica de Ciências Sociais, Coimbra, n. 54, 1999.

SEN, A. Desigualdade reexaminada. Rio de Janeiro: Record, 2001.

SINGER, P. Economia solidária: um modo de produção e distribuição. In: SINGER, P. \& SOUZA, A. (orgs.). A economia solidária no Brasil. A autogestão como resposta ao desemprego. São Paulo: Contexto, 2000 .

SCHUMPETER, J. The Theory of Economic Development. London: Transaction Publishers, 2006 [1934].

THORNTON, P. The Sociology of Entrepreneurship. Annual Review of Sociology, Stanford, n. 25, p. 19-46, 1999.

VALE, G.; WILKINSON, J. \& AMÂNCIO, R. Empreendedorismo, inovação e redes: uma nova abordagem. RAE- Eletrônica, v. 7, n. 1, 2008. 
VOX POPULI. Fatores condicionantes e taxa de mortalidade das MPE 2005 (v. III). S. L. Disponível em http://www.biblioteca.sebrae. com.br/, 2007.

\section{Abstract \\ Looking at micro-entrerprise: elements for an alternative model}

This article seeks to contrast the conventional model of small-scale entrepreneurship, centered around the development of individual abilities, with contributions coming from reflections on associative entrepreneurialism, as evidenced today through the Economics of Solidarity (Economia Solidária) program. The text brings together the major points emerging from critical analysis of small scale entrepreneurship that has been carried out under the auspices of the SEBRAE - Brazilian Service of Support for Small and Micro-enterprise (Serviço Brasileiro de Apoio às Micro e Pequenas Empresas), the predominant conceptual and practical reference in this area in Brazil. This is followed by a view of entrepreneurialism anchored in studies of entrepreneurial ventures in which relational and cooperative elements explicitly play a relevant role. Such elements lead to the shaping of an alternative model, distinct from conventional patterns in terms of understanding and attentiveness to the needs of organizations linked to the popular economy, whether individual or family businesses, or collective endeavors, such as informal production groups, associations and small cooperatives.

Keywords: micro-entrepreneurship, popular economics, informality, Solidary Economics, associative practices. 